\title{
High-pressure advantages in stoichiometric hydrogenation of carbon dioxide to methanol
}

\author{
Rohit Gaikwad, Atul Bansode and Atsushi Urakawa* \\ Institute of Chemical Research of Catalonia (ICIQ), The Barcelona Institute of Science and \\ Technology, Av. Països Catalans 16, 43007 Tarragona, Spain
}

*Corresponding author. Email: aurakawa@iciq.es 


\begin{abstract}
Interplay between three important reaction parameters (pressure, temperature, and space velocity) in stoichiometric hydrogenation of carbon dioxide $\left(\mathrm{CO}_{2}: \mathrm{H}_{2}=1: 3\right)$ was systematically investigated using a commercial $\mathrm{Cu} / \mathrm{ZnO} / \mathrm{Al}_{2} \mathrm{O}_{3}$ catalyst. Their impacts on reaction performance and important ranges of process conditions towards full one-pass conversion of $\mathrm{CO}_{2}$ to methanol at high yield were rationalized based on the kinetics and thermodynamics of the reaction. Under high-pressure condition above a threshold temperature, the reaction overcomes kinetic control, entering thermodynamically controlled regime. Ca. $90 \% \mathrm{CO}_{2}$ conversion and $>95 \%$ methanol selectivity was achieved with a very good yield (0.9-2.4 $\left.\mathrm{g}_{\mathrm{MeOH}} \mathrm{g}_{\mathrm{cat}}^{-1} \mathrm{~h}^{-1}\right)$ at 442 bar. Such high-pressure condition induces the formation of highly dense phase and consequent mass transfer limitation. When this limitation is overcome, the advantage of high-pressure conditions can be fully exploited and weight time yield as high as $15.3 \mathrm{~g}_{\mathrm{MeOH}} \mathrm{g}_{\mathrm{cat}}{ }^{-1} \mathrm{~h}^{-1}$ could be achieved at 442 bar. Remarkable advantages of high-pressure conditions in the terms reaction kinetics, thermodynamics, and phase behavior in the aim to achieve better methanol yield are discussed.
\end{abstract}

Keywords: $\mathrm{CO}_{2}$ hydrogenation; methanol synthesis; high-pressure; kinetics; thermodynamics; $\mathrm{Cu} / \mathrm{ZnO} / \mathrm{Al}_{2} \mathrm{O}_{3}$ 


\section{Introduction}

The ever-increasing energy demand to sustain the industrialization and modern lifestyle has led to depletion consumption of world's current primary energy supply, finite and non-renewable fossil fuels. In parallel, their irreversible consumption resulted in accumulation of carbon dioxide $\left(\mathrm{CO}_{2}\right)$ in the atmosphere, causing the climate to change. For sustainable development of mankind, the carbon cycle has to be closed, and conversion of $\mathrm{CO}_{2}$ into chemical fuels and feedstocks serves as an effective strategy to cope with the interrelated energetic and environmental problems [1]. Heterogeneous catalytic conversion of $\mathrm{CO}_{2}$ to fuels and industrially important chemicals, such as methanol by hydrogenation reaction, offers a unique path to transform a large amount of $\mathrm{CO}_{2}$ in a short span of time by the high reaction rates. The vital roles of methanol as chemical energy carrier and starting material or chemical intermediates are well recognized [2]. However, $\mathrm{CO}_{2}$ is a thermodynamically stable and relatively inert molecule. Its activation typically requires energy inputs, e.g. by the use of elevated pressure and temperature as well as effectual strategies such as innovative catalytic processes [3-6].

$\mathrm{CO}_{2}$ hydrogenation to methanol is exothermic (reaction 1), while the competing reaction, reverse water-gas shift (RWGS, reaction 2), is endothermic [7]. Moreover, CO produced by RWGS may undergo exothermic hydrogenation to form methanol (reaction 3).

$$
\begin{aligned}
& \mathrm{CO}_{2}+3 \mathrm{H}_{2} \rightleftarrows \mathrm{CH}_{3} \mathrm{OH}+\mathrm{H}_{2} \mathrm{O} \quad \Delta \mathrm{H}_{298 \mathrm{~K}, 5 \mathrm{MPa}}=-40.9 \mathrm{~kJ} / \mathrm{mol} \\
& \mathrm{CO}_{2}+\mathrm{H}_{2} \rightleftarrows \mathrm{CO}+\mathrm{H}_{2} \mathrm{O} \quad \Delta \mathrm{H}_{298 \mathrm{~K}, 5 \mathrm{MPa}}=+49.8 \mathrm{~kJ} / \mathrm{mol} \\
& \mathrm{CO}+2 \mathrm{H}_{2} \rightleftarrows \mathrm{CH}_{3} \mathrm{OH} \quad \Delta \mathrm{H}_{298 \mathrm{~K}, 5 \mathrm{Mpa}}=-90.7 \mathrm{~kJ} / \mathrm{mol}
\end{aligned}
$$

In accordance with Le Chàtelier's principle, high-pressure and low-temperature reaction conditions are favorable to achieve high $\mathrm{CO}_{2}$ conversion and methanol selectivity [8]. In fact, 
the advantage and necessity of high-pressure conditions in the synthesis of methanol from syngas $\left(\mathrm{CO}\right.$ and $\mathrm{H}_{2}$ mixture typically containing some fraction of $\left.\mathrm{CO}_{2}\right)$ have been known over the last 90 years [9]. Since 1966, the trend has shifted to lower pressure methanol synthesis ( $<100$ bar) using highly active and economic $\mathrm{Cu}-\mathrm{ZnO}$ based catalysts [10]. For this family of catalysts which are most common for methanol synthesis nowadays, high-pressure advantages in methanol synthesis by the hydrogenation of $\mathrm{CO}$ and particularly $\mathrm{CO}_{2}$ had not been explored and documented for a long time, except the excellent work reported by Ipatieff and Monroe in 1945 for Cu-based catalysts [5]. Recently, we reported a range of highpressure reaction conditions, yielding remarkable almost-full one-pass conversion of $\mathrm{CO}_{2}$ to methanol with high selectivity using $\mathrm{Cu} / \mathrm{ZnO} / \mathrm{Al}_{2} \mathrm{O}_{3}$ catalysts and also to methanol-derived products such as dimethyl ether (DME) by co-presence of an acidic zeolite [11]. The elevated $\mathrm{H}_{2}$ partial pressure (molar ratio, $\mathrm{CO}_{2}: \mathrm{H}_{2}=1:>10$ ), higher than the stoichiometric one $\left(\mathrm{CO}_{2}: \mathrm{H}_{2}=1: 3\right.$, reaction 1$)$, was found kinetically as well as thermodynamically beneficial for methanol synthesis. Employing the reaction pressure of 360 bar (reactants pressure of 331 bar due to the presence of $\mathrm{Ar}$ for $\mathrm{GC}$ analysis), outstanding $\mathrm{CO}_{2}$ conversion (>95\%) and methanol selectivity (>98\%) were achieved at $260{ }^{\circ} \mathrm{C}$ at relatively high gas hourly space velocity (GHSV) of ca. $10000 \mathrm{~h}^{-1}$. With a commercial $\mathrm{Cu}-\mathrm{ZnO}$ based methanol synthesis catalyst, exceptionally high methanol yield of $7.7 \mathrm{~g}_{\mathrm{MeOH}} \mathrm{g}_{\mathrm{cat}}{ }^{-1} \mathrm{~h}^{-1}$ was attained at the expense of lower $\mathrm{CO}_{2}$ conversion (65.8\%) and methanol selectivity (77.3\%). Energy-demanding highpressure conditions are not necessarily disadvantageous in this reaction because of smaller geometrical requirements for the reactor and plant area, which lowers the capital cost and possibly improve safety aspects [4, 11]. Moreover, the energetic cost associated with compression of the reactants is less significant than that required for hydrogen production in the overall process of $\mathrm{CO}_{2}$ hydrogenation to methanol when water electrolysis is assumed as the mean to produce $\mathrm{H}_{2}[12]$. 
Despite the exceptionally high $\mathrm{CO}_{2}$ conversion and methanol selectivity under highpressure conditions and also high process viability in terms of costs and methanol productivity, the reported reaction condition requires recycling or further conversion of unreacted $\mathrm{H}_{2}$ fed in excess. In addition, $\mathrm{CO}$ produced by RWGS should be recycled if methanol selectivity is not sufficiently high. Recycling of precious $\mathrm{H}_{2}$ can only be avoided by achieving its full conversion. In other words, the challenge in this respect is to achieve complete conversion of both $\mathrm{CO}_{2}$ and $\mathrm{H}_{2}$ with high methanol productivity. This goal naturally requires the operation of the reaction at the stoichiometric $\mathrm{CO}_{2}$ to $\mathrm{H}_{2}$ ratio.

Herein, we have thoroughly examined high-pressure reaction conditions (50-480 bar; in reactants pressure of $46-442$ bar) at $220-300{ }^{\circ} \mathrm{C}$ for stoichiometric $\mathrm{CO}_{2}$ hydrogenation, in the aim to identify reaction conditions maximizing $\mathrm{CO}_{2}$ and $\mathrm{H}_{2}$ conversions with high methanol selectivity and/or productivity. A commercial $\mathrm{Cu} / \mathrm{ZnO} / \mathrm{Al}_{2} \mathrm{O}_{3}$ catalyst, optimized for the conversion of syngas to methanol, was employed as catalyst due to its high activity in $\mathrm{CO}_{2}$ hydrogenation to methanol [11]. Tendency and effects of kinetic and thermodynamic controls over the reaction performance are discussed along with the trends in theoretical thermodynamic equilibria to critically evaluate what is achievable with the optimized $\mathrm{Cu} / \mathrm{ZnO} / \mathrm{Al}_{2} \mathrm{O}_{3}$ catalyst and to highlight possible directions of future research in $\mathrm{CO}_{2}$ hydrogenation to methanol.

\section{Experimental}

The details of high-pressure fixed-bed reactor and analytical systems are described elsewhere [4]. Specificity of this work about reactor system, catalyst material, activation procedure and product analysis by gas chromatography is described in Supplementary Material. Continuous $\mathrm{CO}_{2}$ hydrogenation to methanol was tested at four different pressure 
conditions of 50,100, 200, 360, 480 bar (considering 8\% Ar in feed composition, actual total pressure of $\mathrm{CO}_{2}$ and $\mathrm{H}_{2}$ was $46,92,184,331$, and 442 bar, respectively). In this work, GHSV is defined by the volumetric flow rate of inlet stream at normal pressure divided by the reactor volume where the catalyst is packed (including the catalyst volume). A wide range of GHSV conditions $\left(650-100000 \mathrm{~h}^{-1}\right)$ were examined. GHSV is also shown in catalyst-massnormalized unit, in which the value ranges $0.37-49.85 \mathrm{NL} \mathrm{g}_{\mathrm{cat}}{ }^{-1} \mathrm{~h}^{-1}$. For the GHSV calculation in both units, the total flow rate at normal pressure including Ar was used. The vaporized outlet stream were injected to GC every ca. $12 \mathrm{~min}$ for $3 \mathrm{~h}$ at each condition of temperature, pressure and GHSV and an averaged values was taken. The standard deviation of the quantification is presented in Figures S3-S5 in Supplementary Materials. No catalyst deactivation was detected for the duration of catalytic tests performed.

Equilibrium conversion and product selectivity were calculated by the Soave-RedlichKwong (SRK) equation of state (EOS) using Aspen HYSYS V8.6. Modified SRK-EOS binary interaction parameters for $\mathrm{CO}, \mathrm{CO}_{2}, \mathrm{H}_{2}$, methanol and water were taken from the optimized values reported by Heeres and coworkers for methanol synthesis [13]. The calculations were performed by minimization of Gibbs free energy. Methane was not considered in all calculations.

\section{Results and discussion}

\subsection{Effects of temperature under high-pressure conditions}

First, the effects of temperature on $\mathrm{CO}_{2}$ conversion and methanol selectivity were examined at the reactants pressure of 46, 92, 184, 331, and 442 bar (Figure 1). The catalytic tests were performed at a constant GHSV of $10000 \mathrm{~h}^{-1}$, although, as discussed in section 3.2, this reaction parameter can directly influence the residence time of the reactants in the reactor 
and thus catalytic performance. $\mathrm{CO}_{2}$ conversion and methanol selectivity are presented in comparison to the thermodynamic equilibrium values.

Advantages of high-pressure conditions are obvious according to the thermodynamic calculations (Figure 1, dotted lines). At 46 bar, $\mathrm{CO}_{2}$ version varies between $25-30 \%$ with rapidly decreasing methanol selectivity from ca. 90 to $20 \%$ in the temperature window of 220-300 ${ }^{\circ} \mathrm{C}$. At 92 bar, $\mathrm{CO}_{2}$ conversion varies from roughly $50 \%\left(220{ }^{\circ} \mathrm{C}\right)$ to $30 \%\left(300{ }^{\circ} \mathrm{C}\right)$ with very good to moderate methanol selectivity $\left(96.5 \%\right.$ at $220{ }^{\circ} \mathrm{C}$ and $53.4 \%$ at $300{ }^{\circ} \mathrm{C}$ ), whereas at the highest examined pressure of 442 bar, theoretically $\mathrm{CO}_{2}$ can be effectively converted to methanol $\left(98.7 \%\right.$ at $220{ }^{\circ} \mathrm{C}$ and $86.1 \%$ at $\left.300{ }^{\circ} \mathrm{C}\right)$ with very high selectivity for the entire temperature range $\left(>99.9 \%\right.$ at $220{ }^{\circ} \mathrm{C}$ and $99.0 \%$ at $\left.300{ }^{\circ} \mathrm{C}\right)$. At 184 and 331 bar, there was a sudden change in $\mathrm{CO}_{2}$ equilibrium conversion at ca. 230 and $280{ }^{\circ} \mathrm{C}$, respectively (Figure S1 in Supplementary Materials; this change also takes place at 46 and 92 bar but at much lower temperatures at ca. 110 (not shown in the figure) and $160{ }^{\circ} \mathrm{C}$, respectively.). This is due to enhanced $\mathrm{CO}_{2}$ conversion induced by the phase transition and separation (formation of liquid phase) associated with the condensation of the products when the reaction temperature is lower than the transition point. Such phase separation allows $\mathrm{CO}_{2}$ conversion to methanol beyond one-phase equilibrium, as precisely described and demonstrated by Heeres and coworkers [6]. The positive impact of such phase separation on $\mathrm{CO}_{2}$ conversion should become less prominent at higher pressures as noticeable from the equilibrium $\mathrm{CO}_{2}$ conversion curves of 184 and 331 bar. At 442 bar the impact becomes even unnoticeable. This tendency is attributed to the highly dense reactant/product mixture whose density only slightly differs from that of the liquid products and/or it indicates that they are simply miscible at the high-pressure condition.

Experimentally, the general advantages of high-pressure conditions in $\mathrm{CO}_{2}$ conversion, methanol selectivity, and thus methanol yield were confirmed with better catalytic 
performance at higher pressures (Figure 1). Besides methanol, $\mathrm{CO}$ was found as the only major product arising from RWGS reaction. Another product observed was methane with a minor quantity $(<0.8 \%)$. In comparison to the theoretical equilibrium values, larger deviations were observed at lower temperatures for both $\mathrm{CO}_{2}$ conversion and methanol selectivity. These two key indicators of reaction performance showed the maxima at 260-280 ${ }^{\circ} \mathrm{C}$, except methanol selectivity at 46 and 331 bar, and then decreased at higher temperatures. The performance deterioration above the optimum temperature of $260-280{ }^{\circ} \mathrm{C}$ is in accordance with the trend expected by the thermodynamic equilibrium. In the range of 220$300{ }^{\circ} \mathrm{C}$ there were smaller deviations between experimental and theoretical $\mathrm{CO}_{2}$ conversion and methanol selectivity above the optimum temperature, whereas larger deviations were found below the optimum temperature. This implies that thermodynamic equilibrium has been reached or, at least, has significant influence on the reaction performance at the temperatures higher than the optimum temperature at every pressure condition. In other words, at the temperatures below the maxima in catalytic performance, the reaction is kinetically controlled due to poor reaction rates determined by the catalyst at the low temperatures. Theoretically, $\mathrm{CO}_{2}$ conversion can be drastically boosted below $230{ }^{\circ} \mathrm{C}$ at 184 bar. However, such performance enhancement was not observed and a very poor value was obtained at $220{ }^{\circ} \mathrm{C}$. This is a clear indication that the reaction is kinetically controlled at the temperature. To fully benefit from the phase separation, the reaction has to be performed at lower GHSVs to achieve high conversion at low temperatures. Also, it is important to remark that the advantageous phase separation is expected to occur theoretically at higher temperatures under higher pressure conditions. Therefore, high-pressure conditions can be greatly beneficial in this respect to achieve phase separation under kinetically favorable hightemperature conditions. 
The best catalytic performance in terms of $\mathrm{CO}_{2}$ conversion and methanol selectivity was obtained at $260{ }^{\circ} \mathrm{C}$ at 331 bar and at $280{ }^{\circ} \mathrm{C}$ at $46,92,184$, and 442 bar. Maximally performing reaction temperatures were examined at higher and lower GHSV conditions at 331 bar. Interestingly, it was found that the optimum temperature remained the same irrespective of different GHSV conditions (data are not shown). Therefore, we have taken the optimum temperatures at the respective pressures for the following study where the influence of GHSV on the catalytic performance is investigated.

\subsection{Effects of GHSV under high-pressure conditions}

The reaction performance under the high-pressure conditions at the optimum temperature was further evaluated in a wide range of GHSV $\left(650-100000 \mathrm{~h}^{-1}\right.$, equivalent to $0.37-49.85$ NL $\mathrm{g}_{\mathrm{cat}}{ }^{-1} \mathrm{~h}^{-1}$ ). Figure 2 presents $\mathrm{CO}_{2}$ conversion and methanol selectivity as a function of GHSV at 46, 92, 184, 331, and 442 bar, and Figure 3 shows corresponding methanol productivity in terms of weight time yield (WTY) expressed in the unit of $\mathrm{g}_{\mathrm{MeOH}} \mathrm{g}_{\mathrm{cat}}{ }^{-1} \mathrm{~h}^{-1}$. In Figure 2, equilibrium $\mathrm{CO}_{2}$ conversion and methanol selectivity values are indicated by dotted lines.

Clearly, the catalytic performance approaches the thermodynamic limit at the low range of GHSV (i.e. longer residence time). It is, however, not beneficial to over-reducing GHSV as the catalytic performance, especially methanol selectivity, becomes worse. This is mainly due to the formation of side products like methane and ethanol (Tables S2-S6, Supplementary Material). Also, under the very low GHSV conditions, methanol yield is consequently very low. Thus, such reaction conditions are not practically relevant for large-scale industrial operation. The decreased $\mathrm{CO}_{2}$ conversion towards the lowest examined GHSV at 184 bar may be due to additional chemical equilibria involving methane and ethanol, but further investigation is required to identify the exact cause. 
What is striking from the dependence of methanol WTY on GHSV (Figure 3, filled symbols for $100-300 \mu \mathrm{m}$ catalyst particle size) is that there are reaction conditions giving high $\mathrm{CO}_{2}$ conversion and methanol selectivity with methanol WTY close to $1.0 \mathrm{~g}_{\mathrm{MeOH}} \mathrm{g}_{\mathrm{cat}}{ }^{-1} \mathrm{~h}^{-}$ ${ }^{1}$, which is generally considered as an excellent one. At 442 bar, the WTY reached the value of $0.92 \mathrm{~g}_{\mathrm{MeOH}} \mathrm{g}_{\mathrm{cat}}^{-1} \mathrm{~h}^{-1}$ at $4000 \mathrm{~h}^{-1}$ with $88.5 \% \mathrm{CO}_{2}$ conversion and $97.2 \%$ methanol selectivity (Table S2). $0.89 \mathrm{~g}_{\mathrm{MeOH}} \mathrm{g}_{\mathrm{cat}}{ }^{-1} \mathrm{~h}^{-1}$ was obtained at 331 bar also at $4000 \mathrm{~h}^{-1}$ with 83.3\% $\mathrm{CO}_{2}$ conversion and $96.8 \%$ methanol selectivity (Table S3). Similar methanol WTY can be attained at lower pressure, but this requires increasing GHSV due to lower $\mathrm{CO}_{2}$ conversion and methanol selectivity. For example, at 184 bar $0.88 \mathrm{~g}_{\mathrm{MeOH}} \mathrm{g}_{\mathrm{cat}}{ }^{-1} \mathrm{~h}^{-1}$ was obtained at $8000 \mathrm{~h}^{-1}$ with $47.0 \% \mathrm{CO}_{2}$ conversion and $84.8 \%$ methanol selectivity (Table S4). At 92 and 46 bar (Tables S5 and S6), high GHSVs (30000 or $100000 \mathrm{~h}^{-1}$ ) was necessary to achieve $>1.0 \mathrm{~g}_{\mathrm{MeOH}} \mathrm{g}_{\text {cat }}{ }^{-1} \mathrm{~h}^{-1}$ with poor $\mathrm{CO}_{2}$ conversion (28.6 or $20.2 \%$, respectively) and moderate-poor methanol selectivity (53.6 or $19.7 \%$, respectively).

In practice, high $\mathrm{CO}_{2}$ conversion and high methanol selectivity may not be the most critical performance indicator when unreacted $\mathrm{CO}_{2}, \mathrm{CO}$, and $\mathrm{H}_{2}$ can be efficiently recycled. Although larger molar and thus volumetric flow (i.e. high GHSV) demands for higher energetic requirement for the recycling process due to low $\mathrm{CO}_{2}$ conversion, such conditions can greatly improve methanol WTY as discussed above. This was clearly demonstrated under the high GHSV conditions of this work (Figure 3, filled symbols). At $100000 \mathrm{~h}^{-1}$ even at the moderate pressure of 92 bar, a very high WTY of ca. $3 \mathrm{~g}_{\mathrm{MeOH}} \mathrm{g}_{\mathrm{cat}}{ }^{-1} \mathrm{~h}^{-1}$ was achieved and overall excellent WTYs above $4.5 \mathrm{~g}_{\mathrm{MeOH}} \mathrm{g}_{\mathrm{cat}}{ }^{-1} \mathrm{~h}^{-1}$ could be attained above 184 bar. Interestingly, the high-pressure benefit in $\mathrm{CO}_{2}$ conversion was less pronounced at high GHSV, and the conversion values converged to roughly $20-30 \%$ at $100000 \mathrm{~h}^{-1}$ for all examined pressure conditions. In contrast, high-pressure advantage in methanol selectivity 
remained (70.0\% at 331 bar, $47.7 \%$ at 92 bar, $19.7 \%$ at 46 bar) although methanol selectivity decreased remarkably at higher GHSV at 442 bar).

Furthermore, there were clear differences of the GHSV dependency of $\mathrm{CO}_{2}$ conversion at the different pressures. The drop in $\mathrm{CO}_{2}$ conversion was more prominent at higher pressure conditions (331 and 442 bar) upon increasing GHSV, whereas methanol selectivity was not affected by the GHSV variation as much except methanol selectivity at 442 bar. According to the thermodynamic calculation (Figure 1, dotted lines and Figure S1, Supplementary Materials), only under the two high-pressure conditions (331 and 442 bar) product condensation and phase separation (or formation of highly dense phase of the reactants and products at 442 bar due to the rather smooth and continuously changing $\mathrm{CO}_{2}$ conversion profile with increasing temperature) are expected to occur at the reaction temperatures examined. The more significant drop in $\mathrm{CO}_{2}$ conversion at higher GHSVs may be related to the phase behavior. For example, a more severe mass transfer limitation may be induced at higher GHSV conditions, resulting in hindered diffusion of the reactants and products through the catalyst body by the dense/liquid phase formation. In order to verify if there is internal mass transfer limitation or not, we have performed the reaction using the catalyst with the particle size one order of magnitude smaller $(10-20 \mu \mathrm{m})$ than those screened and reported above (100-300 $\mu \mathrm{m})$ at representative pressure $(92,331$, and 442 bar) and GHSV (10000-100000 $\left.\mathrm{h}^{-1}\right)$ conditions. External mass transfer limitation was neglected because the drop in catalytic performance occurs at high GHSV conditions which are favorable for external mass transfer.

Figures 2 and 3 present the effects of catalyst particle size on the catalytic performance and WTY obtained at different GHSVs with smaller catalyst particles (empty symbols and dotted lines) and by larger catalyst particles (filled symbols and solid lines). The reaction performance using the smaller catalyst particles was almost identical to that of the larger ones 
at 92 and 331 bar, but there was a remarkable enhancement of $\mathrm{CO}_{2}$ conversion and methanol selectivity observed at 442 bar. Even at the highest examined GHSV $\left(100000 \mathrm{~h}^{-1}\right)$ high $\mathrm{CO}_{2}$ conversion (65.3\%) and methanol selectivity (91.9\%) were achieved, giving outstanding WTY of $15.3 \mathrm{~g}_{\mathrm{MeOH}} \mathrm{g}_{\mathrm{cat}}{ }^{-1} \mathrm{~h}^{-1}$. At lower GHSV of $30000 \mathrm{~h}^{-1}, \mathrm{CO}_{2}$ conversion was $80.0 \%$ with $96.7 \%$ methanol selectivity, giving WTY of $6.7 \mathrm{~g}_{\mathrm{MeOH}} \mathrm{g}_{\mathrm{cat}}{ }^{-1} \mathrm{~h}^{-1}$. Compared to the theoretical WTY limit $\left(7.7 \mathrm{~g}_{\mathrm{MeOH}} \mathrm{g}_{\mathrm{cat}}{ }^{-1} \mathrm{~h}^{-1}\right)$ defined by the equilibrium conversion and selectivity, the value is very high. At $10000 \mathrm{~h}-1$, WTY of $2.4 \mathrm{~g}_{\mathrm{MeOH}} \mathrm{g}_{\mathrm{cat}}^{-1} \mathrm{~h}^{-1}$ was almost the same as the theoretical value of $2.6 \mathrm{~g}_{\mathrm{MeOH}} \mathrm{g}_{\mathrm{cat}}^{-1} \mathrm{~h}^{-1}$.

These large effects of particle size on the catalytic performance clearly prove that there was a severe internal mass transfer limitation especially at 442 bar as hinted by the great decrease in $\mathrm{CO}_{2}$ conversion at higher GHSVs using the larger catalyst particles. The degree of internal mass transfer was quantitatively evaluated by means of Thiele modulus, effectiveness factor, and Weisz-Prater criterion (Tables S8 and S9, Figure S6, Supplementary Materials). The Weisz-Prater criterion clearly shows the values much larger than 1 at higher GHSVs at 442 bar with the larger catalyst particles. This indicates severe internal mass transfer limitation at 442 bar. The effectiveness factor was 0.3 at $100000 \mathrm{~h}^{-1}$ at 442 bar, showing poor utilization of catalyst surfaces within the particle. The effectiveness of catalyst utilization improves at the lowest space velocity $\left(10000 \mathrm{~h}^{-1}\right)$ of the study and the value of 0.92 was obtained with the catalyst of the larger particle size. When the smaller size catalyst was used, much smaller values of the Weisz-Prater criterion and high value (above 0.95) of the effectiveness factor were obtained, evidencing the effective use of the whole catalyst body for the reaction when the size is reduced by one order of magnitude. At 331 bar, the availability of the catalytic sites are improved as shown by lower values of the Weisz-Prater criterion and by the high values of effectiveness factor. These results strongly suggest that condensation of reactants/products takes place within the catalyst body at the very high- 
pressure conditions examined, inducing the mass transfer limitation. As demonstrated by the extraordinary WTY above $15 \mathrm{~g}_{\mathrm{MeOH}} \mathrm{g}_{\mathrm{cat}}{ }^{-1} \mathrm{~h}^{-1}$, this product condensation can be extremely beneficial if mass transfer limitation can be overcome and/or absent. A higher pressure drops observed at 331 and 442 bar $(\Delta \mathrm{P}=$ ca. $2-5$ bar $)$ than at 92 bar $(\Delta \mathrm{P}=$ ca. 1 bar $)$ also indicate the formation of dense phase under higher pressure conditions.

The reaction mechanisms of methanol synthesis via $\mathrm{CO}_{2}$ hydrogenation, namely via $\mathrm{CO}_{2}$ or CO, are widely debated [14], although a recent study as represented by Studt and coworkers concluded that the major carbon source of methanol is $\mathrm{CO}_{2}$, promoted by the synergetic functions of $\mathrm{Cu}$ and $\mathrm{ZnO}$ [15]. In this study, $\mathrm{CO}$ selectivity increased consistently at higher GHSV (Figure 2 and Tables S2-S5). Detailed mechanistic discussion is out of the scope of this work, but the results indicate that longer residence time enhances methanol selectivity, and that methanol synthesis proceeds via CO produced by RWGS. The same conclusion had been drawn in over-stoichiometric $\mathrm{CO}_{2}$ hydrogenation where excess hydrogen was used $\left(\mathrm{CO}_{2}: \mathrm{H}_{2}=1: 10\right)$ [11]. Still, there is one point which has not been discussed widely, which is the exothermicity of methanol synthesis which can create local hot spots and temperature gradients along the axial and radial directions of the catalyst bed. The reactor we have used has high surface to volume ratio as a kind of microreactor and in principle the geometry is well suited for heat management. However, the generated heat may not be sufficiently removed when WTY of methanol is very high and thus a large heat is generated within the reactor and large temperature increase may occur especially at the catalyst bed where reactants concentration is higher, i.e. close to the inlet of the reactor. The reaction enhanced under such conditions would be endothermic one, i.e. RWGS, thus CO formation could be pronounced in such cases. The trend is indeed what we observed; the higher the GHSV, i.e. higher the WTY consequently in most cases, the higher the CO selectivity. These aspects will be investigated further, but this may be a possible explanation of apparent 
reaction path of methanol synthesis via $\mathrm{CO}$ produced by RWGS under high-pressure conditions because of existence of local hot spots, besides the scenario that $\mathrm{CO}_{2}$ hydrogenation indeed proceeds via $\mathrm{CO}$ at high-pressures.

\section{Conclusion}

Relationships among reaction temperature, pressure, and GHSV in stoichiometric $\mathrm{CO}_{2}$ hydrogenation to methanol over a well-established commercial $\mathrm{Cu} / \mathrm{ZnO} / \mathrm{Al}_{2} \mathrm{O}_{3}$ catalyst were systematically investigated in the aim to understand the advantages given by high-pressure reaction conditions (46-442 bar) and to achieve as high as possible $\mathrm{CO}_{2}$ conversion and methanol selectivity with high methanol productivity towards full conversion to methanol. A strong interplay among kinetics, thermodynamics and phase behavior on the reaction performance was evidenced. At kinetically favorable high temperatures $\left(>260{ }^{\circ} \mathrm{C}\right)$ especially at lower GHSV, it was possible to enter the regime where thermodynamic equilibrium plays dominant roles in determining the catalytic activity. In this regime, high-pressure advantages can be conveniently predicted based on the equilibrium conversion and selectivity. A good WTY of $0.9 \mathrm{~g}_{\mathrm{MeOH}} \mathrm{g}_{\mathrm{cat}}{ }^{-1} \mathrm{~h}^{-1}$ could be achieved at 442 bar with $88.5 \% \mathrm{CO}_{2}$ conversion and 97.2\% methanol selectivity using our standard, larger size of catalyst particles $(100-300 \mu \mathrm{m})$. At high-pressure conditions above 331 bar, the dense phase formation by product condensation limits the overall reaction rate by internal mass transfer. When smaller catalyst particles $(10-20 \mu \mathrm{m})$ are used instead, the limitation can be effectively removed. Thusobtained catalytic performance fully benefits from the high-pressure advantage of high reaction rate (kinetics), high equilibrium conversion (thermodynamics) and enhanced conversion (phase separation). Under these conditions of negligible mass transfer limitations, at 442 bar a very good WTY of $2.4 \mathrm{~g}_{\mathrm{MeOH}} \mathrm{g}_{\mathrm{cat}}{ }^{-1} \mathrm{~h}^{-1}$ could be observed with $87.7 \% \mathrm{CO}_{2}$ 
conversion and $97.6 \%$ methanol selectivity. At a very high GHSV (100000 $\left.\mathrm{h}^{-1}\right)$, an extraordinary WTY of $15.3 \mathrm{~g}_{\mathrm{MeOH}} \mathrm{g}_{\mathrm{cat}}{ }^{-1} \mathrm{~h}^{-1}$ could be achieved.

This work clearly shows favorable reaction conditions towards full one-pass conversion in stoichiometric $\mathrm{CO}_{2}$ hydrogenation to methanol. Development of highly active, new generation catalysts is mandatory to reach this goal by entering to the thermodynamically controlled regime at lower temperature. Another practically important operation condition identified was high GHSV. Even at lowered pressure of 184 bar, a remarkable WTY of 4.5 $\mathrm{g}_{\mathrm{MeOH}} \mathrm{g}_{\mathrm{cat}}{ }^{-1} \mathrm{~h}^{-1}$ could be obtained. Hence, high GHSV conditions at relatively high-pressure were found also beneficial in practice for high-yield methanol synthesis when unreacted $\mathrm{CO}_{2}$, $\mathrm{H}_{2}$, and formed $\mathrm{CO}$ are recycled. In summary, this work has demonstrated that both kinetic and thermodynamic factors play decisive roles in methanol synthesis and also that thermodynamically favorable high-pressure conditions allow reaching the reactivity in the thermodynamically controlled regime and/or with outstanding methanol productivity.

\section{Acknowledgements}

The authors thank the financial support from the ICIQ Foundation and MINECO (CTQ201234153) and also thank MINECO for support through Severo Ochoa Excellence Accreditation 2014-2018 (SEV-2013-0319). Recognition and support by the Catalan government (2014 SGR 893) are greatly acknowledged. RG acknowledges MINECO for FPI predoctoral fellowship (EEBB-I-15-10528).

\section{Appendix A. Supplementary Material}

Supplementary data associated with this article can be found, in the online version, at http://dx.doi.org/XXXX. 


\section{References}

[1] M. Mikkelsen, M. Jorgensen, F.C. Krebs, Energ. Environ. Sci., 3 (2010) 43-81.

[2] G.A. Olah, Angew. Chem. Int. Ed., 44 (2005) 2636-2639.

[3] O.d.Q.F. Araújo, J.L.d. Medeiros, R.M.B. Alves, $\mathrm{CO}_{2}$ Utilization: A Process Systems Engineering Vision, 2014.

[4] A. Bansode, B. Tidona, P.R. von Rohr, A. Urakawa, Catal. Sci. Technol., 3 (2013) $767-$ 778.

[5] V.N. Ipatieff, G.S. Monroe, J. Am. Chem. Soc., 67 (1945) 2168-2171.

[6] J.G. van Bennekom, R.H. Venderbosch, J.G.M. Winkelman, E. Wilbers, D. Assink, K.P.J. Lemmens, H.J. Heeres, Chem. Eng. Sci., 87 (2013) 204-208.

[7] J.A. Dumesic, G.W. Huber, M. Boudart, Principles of Heterogeneous Catalysis, in: Handbook of Heterogeneous Catalysis, Wiley-VCH Verlag GmbH \& Co. KGaA, 2008.

[8] J. Skrzypek, M. Lachowska, M. Grzesik, J. Słoczyński, P. Nowak, Chem. Eng. J. and Biochem. Eng. J., 58 (1995) 101-108.

[9] BASF, German Patents 415 686, 441 433, 462 837, 1923.

[10] J.B. Hansen, P.E. Højlund Nielsen, Methanol Synthesis, in: Handbook of Heterogeneous Catalysis, Wiley-VCH Verlag GmbH \& Co. KGaA, 2008.

[11] A. Bansode, A. Urakawa, J. Catal., 309 (2014) 66-70.

[12] B. Tidona, C. Koppold, A. Bansode, A. Urakawa, P. Rudolf von Rohr, J. Supercrit. Fluids, 78 (2013) 70-77.

[13] J.G. van Bennekom, J.G.M. Winkelman, R.H. Venderbosch, S.D.G.B. Nieland, H.J. Heeres, Ind. Eng. Chem. Res., 51 (2012) 12233-12243.

[14] E.L. Kunkes, F. Studt, F. Abild-Pedersen, R. Schlögl, M. Behrens, J. Catal., 328 (2015) 43-48. 
[15] F. Studt, M. Behrens, E.L. Kunkes, N. Thomas, S. Zander, A. Tarasov, J. Schumann, E.

Frei, J.B. Varley, F. Abild-Pedersen, J.K. Nørskov, R. Schlögl, ChemCatChem, 7 (2015) $1105-1111$. 
Figure 1. Effects of reaction temperature and pressure on $\mathrm{CO}_{2}$ conversion $\left(\mathrm{X}_{\mathrm{CO}_{2}}\right)$ and methanol selectivity $\left(\mathrm{S}_{\mathrm{MeOH}}\right)$ in high-pressure stoichiometric $\mathrm{CO}_{2}$ hydrogenation using commercial $\mathrm{Cu} / \mathrm{ZnO} / \mathrm{Al}_{2} \mathrm{O}_{3}$ catalyst at constant GHSV of $10000 \mathrm{~h}^{-1}\left(5.87 \mathrm{NL} \mathrm{g}_{\text {cat }}^{-1} \mathrm{~h}^{-1}\right)$. Dotted lines show the theoretical equilibrium $\mathrm{CO}_{2}$ conversion and methanol selectivity.

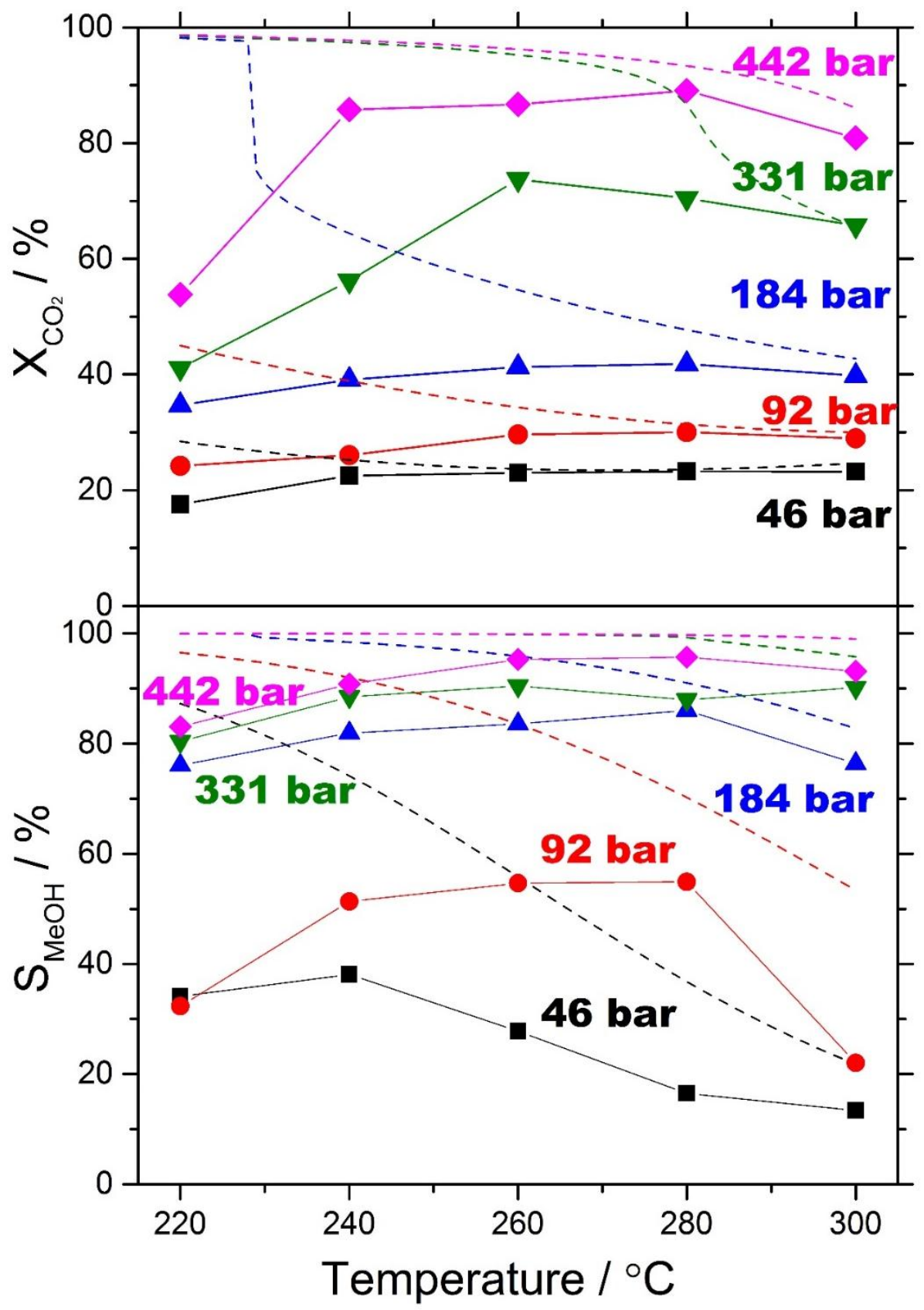


Figure 2. $\mathrm{CO}_{2}$ conversion $\left(\mathrm{X}_{\mathrm{CO}_{2}}\right)$, methanol selectivity $\left(\mathrm{S}_{\mathrm{MeOH}}\right)$ and methanol weight time yield $\left(\mathrm{WTY}_{\mathrm{MeOH}}\right)$ in high-pressure stoichiometric $\mathrm{CO}_{2}$ hydrogenation at different GHSV conditions (650-100000 $\mathrm{h}^{-1}$, equivalent to $\left.0.37-49.85 \mathrm{NL} \mathrm{g}_{\text {cat }}{ }^{-1} \mathrm{~h}^{-1}\right)$ at $280{ }^{\circ} \mathrm{C}$ (46 bar (black), 92 bar (red), 184 bar (blue), and 442 bar (magenta)) and at $260{ }^{\circ} \mathrm{C}$ (331 bar, green) using commercial $\mathrm{Cu} / \mathrm{ZnO} / \mathrm{Al}_{2} \mathrm{O}_{3}$ catalyst. The filled symbols correspond to the catalytic results obtained with the catalyst of 100-300 $\mu \mathrm{m}$ size fraction, while the empty symbols correspond to those obtained with the catalyst of $10-20 \mu \mathrm{m}$ size fraction. The arrows on the right indicate the thermodynamic equilibrium values at the respective temperature and pressure.

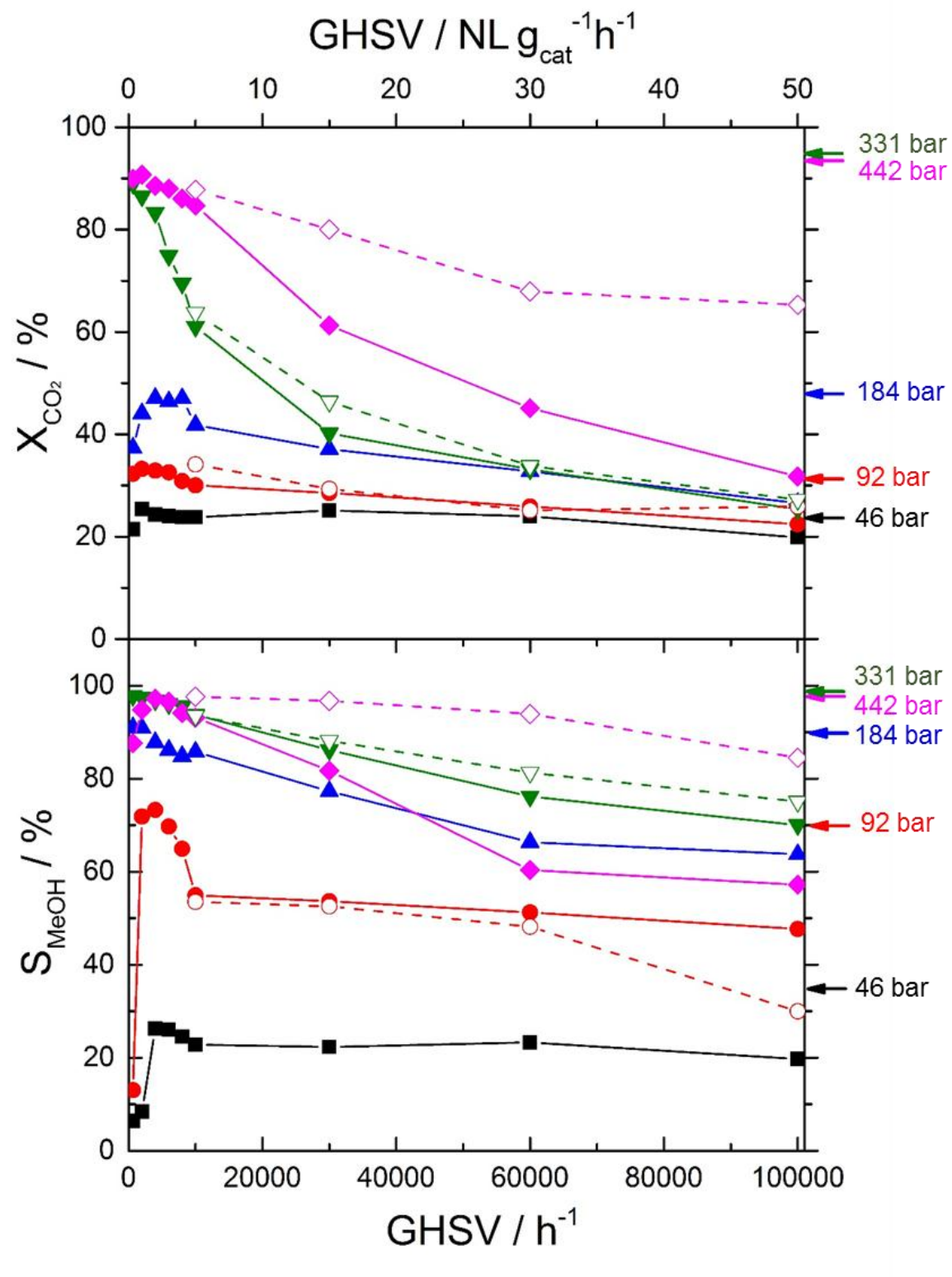


Figure 3. (top) Methanol weight time yield (WTY $\mathrm{WeOH}_{\mathrm{H}}$ in high-pressure stoichiometric $\mathrm{CO}_{2}$ hydrogenation at different GHSV conditions $\left(650-100000 \mathrm{~h}^{-1}\right.$, equivalent to $0.37-49.85 \mathrm{NL}$ $\mathrm{g}_{\mathrm{cat}}^{-1} \mathrm{~h}^{-1}$ ) at $280{ }^{\circ} \mathrm{C}$ (46 bar (black), 92 bar (red), 184 bar (blue), and 442 bar (magenta)) and at $260{ }^{\circ} \mathrm{C}$ (331 bar, green) using commercial $\mathrm{Cu} / \mathrm{ZnO} / \mathrm{Al}_{2} \mathrm{O}_{3}$ catalyst. The filled symbols correspond to the catalytic results obtained with the catalyst of 100-300 $\mu \mathrm{m}$ size fraction, while the empty symbols correspond to those obtained with the catalyst of $10-20 \mu \mathrm{m}$ size fraction. (bottom) $\mathrm{WTY}_{\mathrm{MeOH}}$ at equilibrium conversion and selectivity at the different GHSVs.

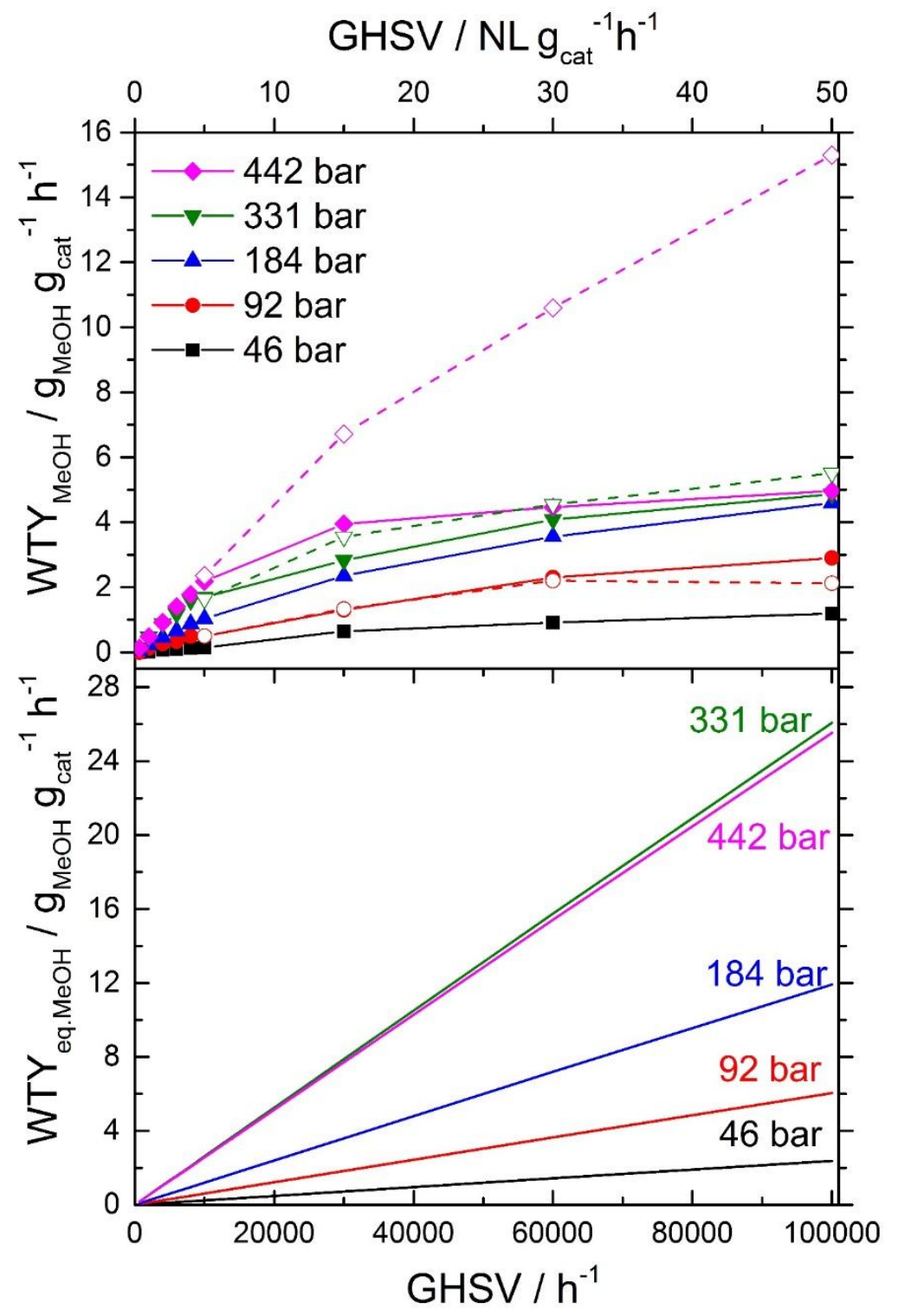

